[CATHERINE LANOË]

Maître de conférences em História Moderna na Université d'Orléans

E-mail: catherine_lanoe@hotmail.com

Tradução

[THIAGO MATTOS]

Pós-doutorando em Letras Estrangeiras e Tradução na Universidade de São Paulo

E-mail: thiagomattos.lit@gmail.com

\title{
A maquiagem tem um gênero? Olhares sobre a maquiagem masculina
}


Como atestam hoje muitos artigos e peças publicitárias, o uso de cosméticos e de maquiagem não é mais exclusividade feminina: os produtos destinados aos homens ganharam as prateleiras das perfumarias. Ao mesmo tempo, como podemos perceber nas fotografias de moda e nas ruas das grandes cidades, esses produtos eventualmente ajudam a forjar aparências que tornam mais imprecisas as delimitações entre as identidades sexuais. Alguns observadores, influenciados pelas reflexões sobre gênero, concluem que se trata de uma outra relação com o corpo, com o sexo biológico, baseada sobre uma maior liberdade de expressão do indivíduo - a não ser que a expressão da individualidade tenha se tornado, ao contrário, uma nova obrigação social... De todo modo, é inegável que ocorreram mudanças nas representações das identidades sexuais em relação aos últimos dois séculos e em relação às práticas de maquiagem, quase exclusivamente femininas até recentemente.

Essa polarização nem sempre foi tão radical no ocidente moderno. Ela é fruto de uma construção realizada entre os séculos XVI e XVIII, e nos leva a afirmar o quanto as marcas sexuais das aparências e seus artifícios devem ser historicizados, sendo produtos de uma dada cultura (LANOË, 2008). Nesse caso, como "o rosto maquiado é a busca de uma 23I ] identidade mais propícia" à relação social, as diferentes formas engendradas pela sociabilidade dessa época constituem um lugar privilegiado de observação (LE BRETON, 1992, p. 222). Examinaremos, portanto, o uso de alguns produtos emblemáticos: maquiagem (pó de arroz e rouge) de um lado; e pó para perucas de outro. É inegável que os retratos (pintados, gravados ou literariamente descritos) constituem uma fonte bastante rica. No entanto, como não podem ser considerados representações fotográficas, tampouco assegurar a reprodução de práticas reais, devem ser confrontados com fontes que permitam acessar diretamente as práticas de consumo, os usos e as mudanças. Esta reflexão pretende demonstrar que ao longo desse período os cosméticos pouco a pouco deslocaram-se para o universo feminino e que a condenação da maquiagem masculina constitui o corolário de tal movimento.

\section{Maquiagens e identidade sexual}

$\mathrm{Na}$ França entre os séculos XVI e XVIII, marcada pela autoridade da corte que dita as normas da aparência, os cosméticos não são usados necessariamente para expressar ou reforçar identidades sexuais. Os manuais de receitas, que ensinam a confeccionar os cosméticos em casa, fornecem vários testemunhos nesse sentido. Ainda que alguns desses cosméticos sejam explicitamente destinados ao público feminino, outros são destinados aos grandes, isto é, "às pessoas de qualidade" (BARBE, 1992), como escreve o perfumista Simon Barbe em 1699, sem se aprofundar em maiores detaIhes. Assim como alguns retratos também confirmam, o arsenal cosmé- 
tico desse momento é potencialmente comum aos dois sexos. Ainda que possamos afirmar que o uso da maquiagem era mais frequente entre as mulheres, o consumo de pó para perucas aumenta exponencialmente no século XVIII entre ambos os sexos.

Na corte, o uso desses produtos visa colocar-se em conformidade à ordem social e política do reino: as relações hierárquicas estabelecidas ditavam as regras de aparência e de identificação de cada grupo. Clarear o rosto é atributo da classe ociosa, a nobreza, que lança mão de diferentes artifícios para tanto. Seja em forma de pó, seja em forma de creme, o rosto e o colo são cobertos de branco, enquanto o rouge é espalhado nas maçãs do rosto, acentuando por contraste o branco da face. 0 rosto se torna uma verdadeira máscara, impenetrável e impessoal, propícia às competições que sustentam as relações sociais da corte e a atmosfera de desconfiança então reinante.

Por mais forte que seja a necessidade de modelar o rosto, deve-se respeitar certos limites tácitos de moderação, de maneira que a superioridade pareça natural, consubstancial à condição de nobreza. Ora, como em muitos casos tal moderação não é levada em conta, o exagero rapidamente dá origem a críticas. A crítica feita por Théodore Agrippa d'Aubigné em 1616 tornou-se bastante conhecida por sua violência. Henrique III e seus cortesãos, maquiados e carregados de joias, corromperiam e inverteriam a obra de Deus, mas também a ordem política, a ordem social e a ordem das aparências, que deveriam reproduzir a homologia entre o céu e a terra. No lugar de um rei, Aubigné vê um animal, um estrangeiro, uma prostituta, uma mulher... (D'AUBIGNÉ, 1931, p. 60).

A confissão protestante do poeta ajuda a explicar a virulência do ataque. É importante notar, de todo modo, que suas afirmações parecem inaugurar a necessidade de estabelecer marcas sexuais mais nítidas, às quais corresponderia uma polarização crescente em relação ao uso de cosméticos. Como atestam alguns textos dos séculos XVII e XVIII, as mulheres tornam-se alvo das críticas contra a maquiagem, críticas cujos fundamentos mudam ao longo do tempo. A imagem da pecadora que corrompe a obra de Deus, por exemplo, dá lugar a metáforas secularizadas que reificam e ridicularizam a mulher maquiada, vendo nela uma roda de carruagem, um pagode pintado, uma estátua de gesso ${ }^{2} .$. Ainda que tais palavras não indiquem que os homens pararam definitivamente de fazer uso de maquiagem, explicitam que a feminização de tal artifício é evidente, e que essa feminização torna-se constitutiva do desprezo contra os homens maquiados. Assim, quando Saint-Simon (1990, p. 75) e outros observadores $^{3}$ descrevem, no final do reinado de Luís XIV, a maquiagem de Monsieur, irmão do rei, desdenhosamente o comparam a uma mulher, deixando subentendida a referência à homossexualidade. 


\section{A maquiagem, atributo das mulheres}

0 deslocamento da maquiagem para o universo feminino se confirma no século das Luzes. A sociedade da corte não é mais o modelo, e os cânones que ela edificara não exercem mais o mesmo poder coercitivo sobre as aparências masculinas além do perimetro de Versalhes. Ao contrário, novas sociabilidades mundanas aparecem no espaço público parisiense - salões, academias, debates -, propiciando trocas mais espontâneas, mais sinceras, e promovendo fisionomias pretensamente mais naturais. Os homens da aristocracia aplicam em suas perucas grandes quantidades de pó branco, de 9 a 10 libras (4,5 a 5 quilos aproximadamente) por mês, mas raramente se maquiam. Cortesão cuidadoso com sua aparência, o duque de Coigny compra apenas dois potes de rouge no ano de 1779, enquanto compra nada menos do que 238 libras (cerca de 117 quilos) de pó para peruca no mesmo ano. Nas ruas de Paris, constata-se a mesma coisa. Se os burgueses, os artesãos e os donos de boutiques se convertem à moda da peruca empoada (sinal de distinção física e de superioridade sobre o restante da população), o mesmo não acontece em relação à maquiagem, utilizada apenas (e ocasionalmente) pelas suas esposas.

Em torno de 1750-1760, com o desenvolvimento da moda feminina, a polarização sexuada de certos adereços faciais já se faz presente. 233 ] A imprensa de moda, que estabelece uma relação estreita entre as muIheres, a cultura comercial e a moda, reforça tal polarização. Os homens que ainda não abandonaram a maquiagem são objeto de ataques cada vez mais virulentos e sexualmente orientados (JONES, 2004). Muitos autores fustigam tais indivíduos, que se tornariam mulheres ao adotar seus hábitos e assuntos: conversam sobre fitas, pompons, penachos; recebem visitas no cômodo em que preparam sua toalete (COYER, 1748). Na literatura e na iconografia, o personagem do petit-maître, jovem elegante e pretensioso, torna-se o perfeito representante desse mimetismo. Tomando emprestados do universo feminino pós e pomadas para os cabelos, perfumes, enfeites e maquiagens, esse homem seria "efeminado", "travesti", até "ridículo", "camaleônico" ou mesmo "macaco" (CARACCIOLLI, 1760). Na Grã-Bretanha, os anos 1770 também são atravessados por excessos e subentendidos. Os Macaronis, jovens aristocratas imbuídos de cultura italiana e francesa, adotam, contrariamente à nova sobriedade masculina, trajes chamativos, colados ao corpo, perfumes, pós, pomadas de cabelo, perucas enormes, ostentando um topete frontal e um rabo-de-cavalo na parte de trás (RAUSER, 2004).

A crítica subjacente a esse tipo de comportamento ecoa o discurso de Aubigné, mas traz também novas dimensões e interpretações. Primeiramente, revela que a ordem da natureza biológica e a ordem de gênero substituíram a ordem de Deus na condenação dos usos masculinos de adereços e maquiagens. Reclama-se que sejam estabelecidas diferenciações sexuais mais nítidas. Em seguida, revela também que os critérios de bom 
gosto mudaram em relação às práticas e às representações do corpo. Com efeito, mesmo que as aparências masculinas permaneçam artificiais com o uso de pó nas perucas, o natural e a autenticidade dos rostos se impõem como valores de uma nova distinção que leva ao descrédito de todos os dispositivos artificiais... relegando-os às mulheres.

0 petit-maître francês encarna uma figura social predominantemente marginal. Origina-se de um exagero, de uma construção fantasmática que evidencia certas mudanças da sociedade e as crenças que surgem daí. Menos "guerreiro" que o século XVII, preferindo trocas relativamente pacificas, o século das Luzes renovou as formas de sociabilidade, atribuindo um lugar inédito às mulheres, mesmo que algumas delas ocupem as antessalas do poder real. Certos elementos que aterrorizam alguns representantes da raça masculina contribuem para promover um discurso misógino sobre a "indolência" da sociedade e inspiram o desejo de ver estabelecidas firmemente as fronteiras sexuais da aparência (VILLEMERT, 1759).

No final do século, tal desejo parece parcialmente satisfeito. As receitas de cosméticos disponiveis na Société Royale de Médecine mostram uma clara polarização. A maioria das preparações, inclusive de maquiagem, é exclusivamente dedicada às mulheres. São raras as receitas destinadas aos 234 ] homens: ao lado de algumas pomadas que supostamente favoreceriam 0 crescimento capilar e permitiriam renunciar à peruca, somente três receitas de sabão de barbear ${ }^{4}$. A linha divisória está firmemente demarcada: às mulheres são destinados os apetrechos de maquiagem e todos os demais cosméticos, mesmo quando considerados inócuos ou fúteis; aos homens, cuja aparência deve demonstrar uma nova austeridade, sabão e água, indispensáveis para a lógica higienista então nascente. Nos anos 1810-1820, a onda dandy, que se apropria de certos usos e produtos femininos, pode ser inicialmente considerada como uma alternativa material às normas de sobriedade da aparência masculina. No entanto, mais uma vez surgem os discursos e as caricaturas contra o exagero dos gestos e das silhuetas, construindo e difundindo uma imagem que se contrapõe diretamente à imagem desses homens efeminados.

Ao terminar esta reflexão, convém lembrar que a condenação da maquiagem masculina cresce ao longo do Antigo Regime, à medida que os usos dos cosméticos, assim como de outros adereços do corpo, deslocam-se para o mundo das mulheres e que a dominação masculina, desprezando inúmeras práticas femininas, impõe aparências sexuais nitidamente diferenciadas. Como construção fantasmática, o petit-maître do século XVIII é consequentemente uma expressão das distâncias e das tensões que existem entre as práticas e as representações. Os historiadores, no entanto, podem se queixar de que a figura do petit-maitre tenha sido às vezes tomada como denominador comum e tenha se tornado uma referência homogeneizadora para retratar as aparências masculinas das Luzes. 


\section{NOTAS}

'Esta é uma versão em português do artigo "Le fard a-t-il un genre? Regards sur le maquillage masculin", originalmente publicado no catálogo da exposição Tenue correcte exigée! Quand le vetêment fait scandale, em cartaz no Museu de Artes Decorativas em Paris, de $1^{\circ}$ de dezembro de 2016 a 23 abril de 2017, sob direção de Denis Bruna.

2 Para um panorama da violência da condenação religiosa da maquiagem e dos adereços em geral, cf. Félix Grenaille de Chatounières (1639-1640). Para um exemplo de condenação que enfatiza o caráter "ridículo" dos usos exagerados de maquiagem no fim do século XVIII, cf. Encyclopediana, ou dictionnaire encyclopédique des Ana, suplemento da Encyclopédie méthodique, entrada "Fard" (FARD, 1791).

${ }^{3}$ Sua toalete, escreve um anônimo, "era como a de uma mulher. Usava até pó de arroz e rouge" (MANUSCRITOS, sem data.).

${ }^{4}$ Arquivos da Société Royale de Médecine [Sociedade real de medicina], seção de "Remèdes secrets" [Remédios secretos].

\section{REFERÊNCIAS}

BARBE, Simon. Le Parfumeur royal ou l'art de parfumer avec les fleurs et composer toutes sortes de parfums, tant pour l'odeur que pour le gout. Paris: edições Simon Augustin Brunet, 1699; reimpressão em Paris: Aux Amateurs de Livres, Klincksiek, 1992.

CARACCIOLI, Louis Antoine de. Le Livre des quatre couleurs. Paris: Duchêne, 1760.

CHATOUNIĖRES, Félix Grenaille de. L'Honnête Fille. 3 v. Paris: J. Pasié, 1639-1640.

COYER, Gabriel François. L'Année merveilleuse ou les Hommes-femmes. Paris, 1748.

D'AUBIGNÉ, Théodore Agrippa. Les Tragiques. Paris: Garnier, 1931 [1616].

FARD. In: ENCYCLOPEDIANA, ou dictionnaire encyclopédique des Ana, suplemento da Encyclopédie méthodique. Paris: Panckoucke, 1791.

JONES, Jenniger. Sexing La Mode: Gender, Fashion and Commercial Culture in Old Regime France. Oxford: Berg Publishers, 2004.

LANOË, Catherine. La Poudre et le Fard. Une histoire des cosmétiques de la Renaissance aux Lumières. Seyssel: Champ Vallon, 2008.

LE BRETON, David. Des Visages. Paris: Métaillé, 1992.

MANUSCRITOS franceses. Paris, BnF, novas aquisições 7909.

RAUSER, Amelia. Hair, Authenticity, and the Self Made Macaronis. Eighteenth-Century Studies, v. 38, n. 1, p. 101-117, 2004.

SAINT-SIMON. Mémoires. Paris: Gallimard, 1990.

VILLEMERT, Pierre-Joseph Boudier de. L'Ami des femmes. Paris: Quai des Augustins, 1759. 